\title{
Prevalence and risk factors associated with Cryptosporidium spp. infection in local breed of dogs in Enugu State, Nigeria
}

\author{
Ukamaka U. Eze ${ }^{1}$, Ikenna O. Ezeh² ${ }^{2}$ Terry A. Nzeakor ${ }^{2}$, Samuel C. Attama ${ }^{1}$, Ekene V. Ezenduka ${ }^{3}$ and \\ Denchris N. Onah²
}

1. Department of Veterinary Medicine, Faculty of Veterinary Medicine, University of Nigeria, Nsukka, Nigeria;

2. Department of Veterinary Parasitology and Entomology, Faculty of Veterinary Medicine, University of Nigeria, Nsukka, Nigeria; 3. Department of Veterinary Public Health and Preventive Medicine, Faculty of Veterinary Medicine, University of Nigeria, Nsukka, Nigeria.

Corresponding author: Ikenna O. Ezeh, e-mail: ikenna.ezeh@unn.edu.ng

Co-authors: UUE: ukamakauchenna.eze@unn.edu.ng, TAN: terry.ezeudu@unn.edu.ng, SCA: samuelchijioke16@gmail.com, EVE: ekene.ezenduka@unn.edu.ng, DNO: denchris.onah@unn.edu.ng

Received: 03-12-2018, Accepted: 03-04-2019, Published online: 31-05-2019

doi: 10.14202/vetworld.2019.729-734 How to cite this article: Eze UU, Ezeh IO, Nzeakor TA, Attama SC, Ezenduka EV, Onah DN (2019) Prevalence and risk factors associated with Cryptosporidium spp. infection in local breed of dogs in Enugu State, Nigeria, Veterinary World, 12(5): 729-734.

\begin{abstract}
Aims: Cryptosporidiosis is an important zoonotic disease of major public and veterinary concern. The disease affects humans and a variety of animal species including the domestic dog. This study aimed to determine the prevalence and risk factors associated with Cryptosporidium spp. infection in local breed of dogs from different homes and those presented at veterinary hospitals and clinics in Enugu State, Nigeria.

Materials and Methods: A total of 203 fresh fecal samples were collected from domestic dogs in six local government areas in Enugu State from February 2015 to August 2015. All the samples were examined using the formol-ether sedimentation method. Fecal smears were then stained by the modified Ziehl-Neelsen technique and examined under direct light microscopy.

Results: A total of $74(36.5 \%)$ dogs were infected with Cryptosporidium spp. oocysts. There was a strong association $(\mathrm{p}<0.05)$ between the presence of Cryptosporidium spp. oocysts and management practices. However, there was no statistically significant association ( $\mathrm{p}>0.05$ ) between the presence of Cryptosporidium spp. oocysts and age, sex, and fecal consistency.

Conclusion: The findings of this work suggest that domestic dogs in Enugu State harbor and shed Cryptosporidium spp. oocysts in the environment, especially those managed semi-intensively. Such fecal shedding is particularly so and of greater zoonotic and epidemiological importance in animals that do not show clinical signs and therefore not treated. They, therefore, pose a greater public health risk, especially to immune-compromised humans and animals. Public education on the zoonotic implication of this protozoan infection is of paramount importance in Enugu State, in particular, and Nigeria, in general, considering the closeness of dogs and man.
\end{abstract}

Keywords: Cryptosporidium, dogs, modified Ziehl-Neelsen techniques, Nigeria, prevalence, risk factor.

\section{Introduction}

Cryptosporidium spp. is an apicomplexan protozoon of the order Eucocidiorida, subclass Coccidiansina, and class Sporozoasida [1]. This intracellular parasite affects the epithelial cell linings of the digestive system of a wide variety of mammalian hosts, including domestic dogs where they cause mucoid to bloody diarrhea and even death $[2,3]$. It is one of the most common intestinal protozoan parasites of animals and man, particularly in children and immunocompromised patients [4]. The parasite is the cause of large water-borne and food-borne outbreaks of gastroenteritis and is strongly associated with

Copyright: Eze, et al. Open Access. This article is distributed under the terms of the Creative Commons Attribution 4.0 International License (http://creativecommons.org/licenses/by/4.0/), which permits unrestricted use, distribution, and reproduction in any medium, provided you give appropriate credit to the original author(s) and the source, provide a link to the Creative Commons license, and indicate if changes were made. The Creative Commons Public Domain Dedication waiver (http://creativecommons.org/ publicdomain/zero/1.0/) applies to the data made available in this article, unless otherwise stated. diarrhea, which may be severe in AIDS patients [4]. The close relationship between man and his domestic pets, particularly dogs, makes transmission of zoonotic diseases very easy, especially those that could be acquired through environmental contamination such as cryptosporidiosis. Cryptosporidium canis is the most frequently identified species of Cryptosporidium spp. in dogs and its isolation in human patients from both developed and under-developed countries suggests that it is zoonotic [3,5-7]. For instance, studies have shown that both dogs and children from the same household were infected with $C$. canis, further highlighting the zoonotic importance of the disease [8]. Cryptosporidium spp. have been shown, in a recent data by the global enteric multicenter study on the burden and etiology of childhood diarrhea in developing countries, to be the leading causes of moderate to severe diarrhea in children $<2$ years of age [9]. Furthermore, the resistant stage (oocyst) produced by Cryptosporidium spp. is stable and can survive for weeks to months in the environment. Experimental 
studies suggest that even a single oocyst carries some probability of causing infection [10]. Canine intestinal cryptosporidiosis can result in serious or even fatal enteritis with diarrhea which may be hemorrhagic and accompanied by tenesmus, vomiting, abdominal pain, and inappetence, resulting in poor health, impaired development, and colitis, especially in puppies and immunocompromised adult dogs, and death could result from excessive loss of electrolyte and dehydration [11-14].

In Nigeria, especially in rural areas, most dog owners have little or no chance of providing orthodox veterinary health care for their pets as a result of a dearth or complete lack of veterinarians. This situation results in domestic dogs harboring parasitic and other infections including zoonoses; thus, posing public health risks to humans, especially children who play around in the environments that are usually contaminated with stray dog feces $[8,15]$.

The emergence of Cryptosporidium spp. as one of the leading causes of death in HIV/AIDS patients $[16,17]$ has resulted in increased research on the prevalence of and infection caused by the parasite in domestic animals [18,19]. Despite the reported high prevalence of the infection in domestic animals [18-22], cryptosporidiosis is usually not included as a possible cause of gastroenteritis and therefore omitted in the routine differential diagnosis of gastroenteritis in domestic dogs. The importance of enteric protozoan infections in dogs and their public health implications cannot be overemphasized. However, there is a dearth of information and research on cryptosporidiosis in domestic dogs in Enugu State, Nigeria, irrespective of the fact that dog keeping is common and that Enugu State is one of the states with moderately high prevalence (approximately $4 \%$ ) of HIV/AIDS in Nigeria [23].

This study was, therefore, designed to determine the prevalence and risk factors associated with the shedding of Cryptosporidium spp. oocysts in feces of dogs in Enugu State, Nigeria.

\section{Materials and Methods}

\section{Ethical approval and informed consent}

Consent was sought and was willingly granted by pet owners in the study area before their pet animals were included in the study. Free treatment was administered to clinically infected animals as an incentive to the owners for willingly allowing their animals to be used for the study. The experimental protocol was approved by the Experimental Animal Ethics Committee of the University of Nigeria, Nsukka.

\section{Study area}

The study was undertaken in Enugu State (Figure-1) which covers approximately $7617.82 \mathrm{~km}^{2}$ and is located between latitude $6^{\circ} 45^{\prime}$ and $7^{\circ} \mathrm{N}$ and longitude $7^{\circ} 12.5^{\prime}$ and $7^{\circ} 36^{\prime} \mathrm{W}$ in the Southeast geopolitical zone of Nigeria. It has three senatorial zones and 17 local government areas (LGAs). Simple random

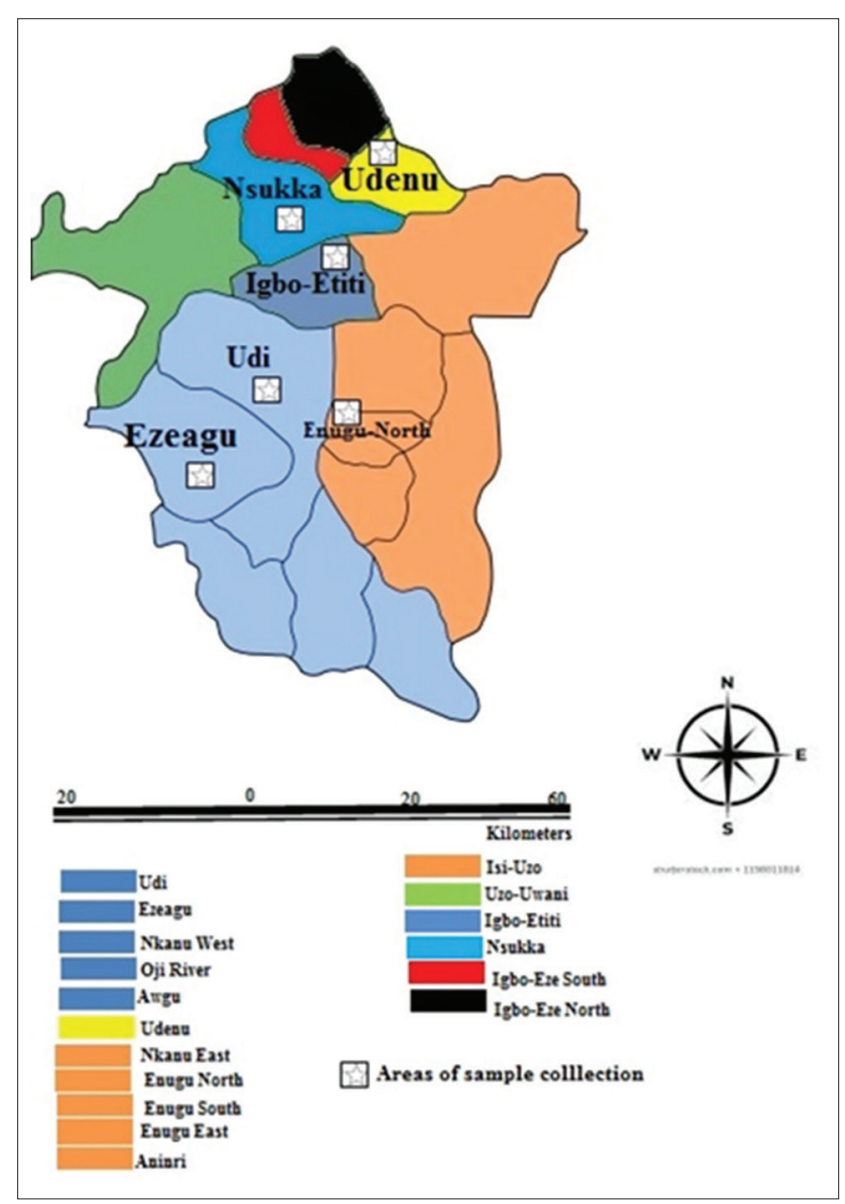

Figure-1: Map of Enugu showing areas of sample dogs collection.

sampling technique was used to select two senatorial zones - Enugu West and Enugu North of the three senatorial zones in Enugu State. Samples were then collected from dogs from similarly randomly selected homes, veterinary hospitals, and clinics in three randomly selected LGAs in the two senatorial zones. Geographic positioning system was used to record the coordinates of the study area; thereafter, Geographic Information System - ArcView 3.3 [24] was used to construct the map showing areas of sample collection.

\section{Sample collection}

Fresh fecal samples were collected from January to August 2015 from the randomly selected homes of dog owners, veterinary hospitals, and clinics. A total of 203 dogs were sampled in this study. Fecal samples were collected per rectum from each dog using a well-lubricated gloved finger into pre-labeled plastic containers. Animal identity including sex, age, and source was recorded for each dog. The management practices were graded as intensive for those dogs that stay in kennels and reside in a fenced compound and can only move around in the compound when released, while those that stay in kennels or chains but reside in compounds that are not fenced and can move around in the neighborhood when released were regarded as semi-intensive. 


\section{Parasitological analysis}

All stool samples were examined macroscopically, and their characteristics and consistency were recorded. The fecal consistencies were then categorized as formed, pasty or watery (diarrheic). The stool samples were then preserved at room temperature $\left(25-28^{\circ} \mathrm{C}\right)$ in $5 \%$ formol saline until analyzed. The samples were concentrated by the formalin-ethyl acetate sedimentation technique [25], and then, thin smears of the sediments were made on glass slides, air-dried, and fixed with methanol. For the detection of Cryptosporidium spp. oocysts, modified Ziehl-Neelsen staining was performed, and the slides were examined using the oil immersion objective at $1000 \times$. For quality control, all examinations were repeated twice by two experienced microscopists. The Cryptosporidium spp. was identified based on the oocysts staining characteristics.

\section{Statistical analysis}

Results were analyzed by descriptive statistics and presented as percentages using tables and pie charts. GraphPad Prism statistical package version 5.2 for Windows (GraphPad Software, La Jolla, California, USA, www.graphpad.com) was used to analyze generated data, where Chi-square test was used to determine the association between the presence of Cryptosporidium spp. oocysts and management practice; presence of Cryptosporidium spp. oocysts and sex; and presence of Cryptosporidium spp. oocysts and fecal consistency. Odds ratio was used to determine the strength of association between the variables. Statistical significance was accepted at $\mathrm{p}<0.05$.

\section{Results}

In positive samples, Cryptosporidium spp. oocysts were seen as red staining round bodies (Figure-2) about 5-8 $\mu \mathrm{m}$ against a blue background.

\section{Distribution of the parasite oocysts according to localities}

Of the 203 fecal samples, 74 (36.5\%) were positive for intestinal protozoan parasites. The distribution of the positive samples according to the LGAs was 22 (29.7\%), 15 (20.3\%), 11 (14.9\%), 10 (13.5\%), $9(12.2 \%)$, and $7(9.5 \%)$ for Udenu, Igbo-Etiti, Ezeagu, Udi, Nsukka, and Enugu North LGAs, respectively (Table-1).

\section{Prevalence of Cryptosporidium spp. in fecal samples of dogs and their associated risk factors}

Of 203 fecal samples examined, 74 (36.5\%) contained oocysts of Cryptosporidium spp. There was a strong association $(\mathrm{p}<0.05)$ between the presence of Cryptosporidium spp. oocysts and management practice (Figure-3). This study was done in rural areas where most people do not have access to good toilet facilities and they defecate in the bushes around residential buildings. Dogs managed semi-intensively roam the neighborhood, defecate indiscriminately, and equally have access to human feces in the environment. This

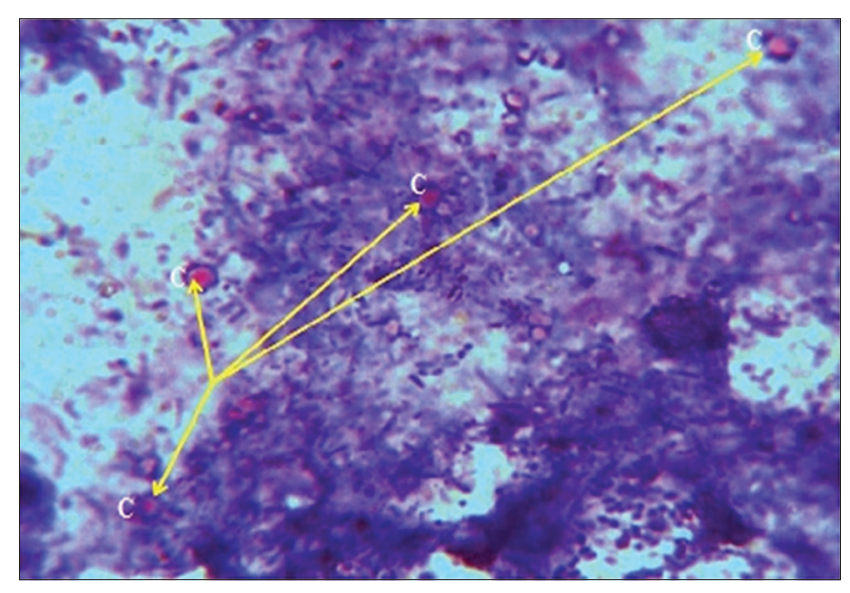

Figure-2: Cryptosporidium spp. oocysts ( $\mathrm{C}=$ arrows) stained by modified Ziehl-Neelsen technique $(1000 \times)$.

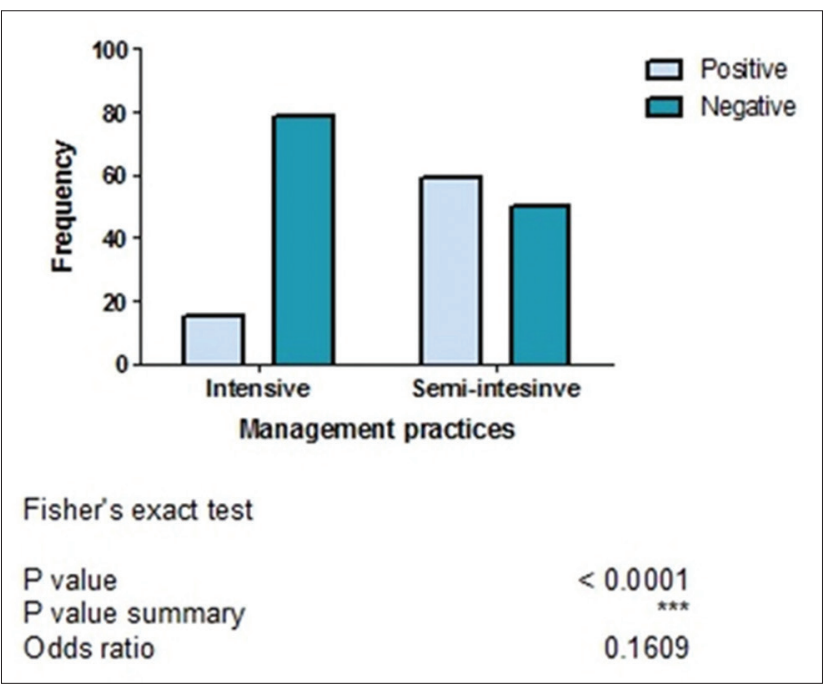

Figure-3: Association between the presence of Cryptosporidium spp. and management practices of sampled dogs in Enugu State, Nigeria.

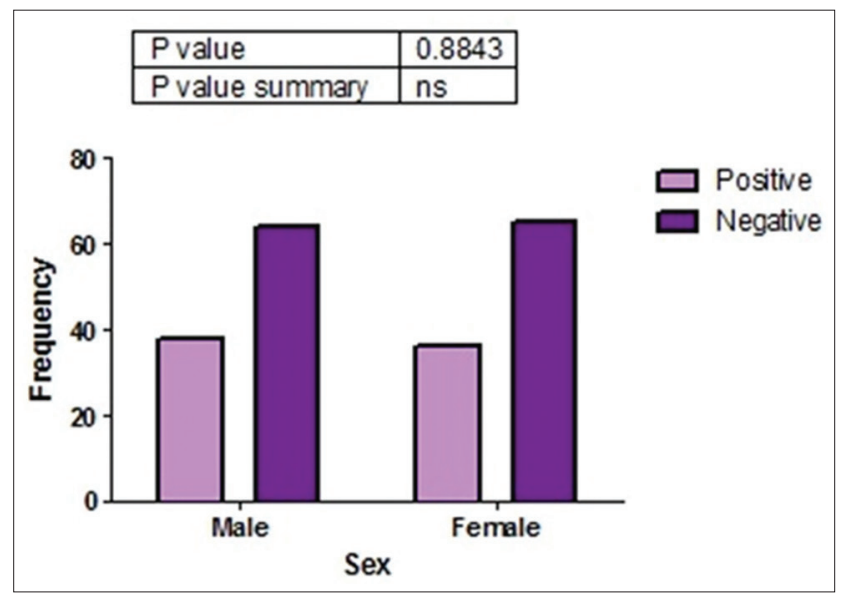

Figure-4: Association between the presence of Cryptosporidium spp. and sex of sampled dogs in Enugu State, Nigeria.

behavior encourages contamination of the environment by both man and dogs and thus increases the chances of naïve dogs getting infected with Cryptosporidium spp. and probably other gastrointestinal parasites. Statistical analysis showed that there was no significant association 
( $p>0.05$ ) between the presence of Cryptosporidium spp. oocysts and sex (Figure-4). Furthermore, there was no significant association between the presence of Cryptosporidium spp. oocysts and fecal consistency (Figure-5). Therefore, the greatest risk factor for the maintenance and transmission of cryptosporidiosis in the study area was free roaming of dogs and open-air defecation by humans and dogs.

\section{Discussion}

The prevalence of Cryptosporidium spp. oocysts in feces of local dogs in Enugu State, Nigeria, was

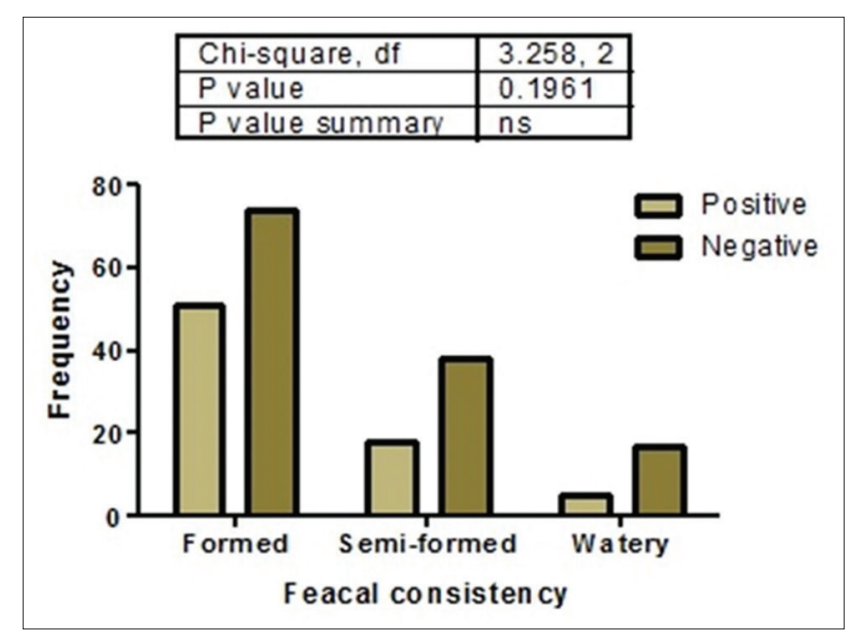

Figure-5: Association between the presence of Cryptosporidium spp. and fecal consistency of the feces of dogs sampled in Enugu State, Nigeria.

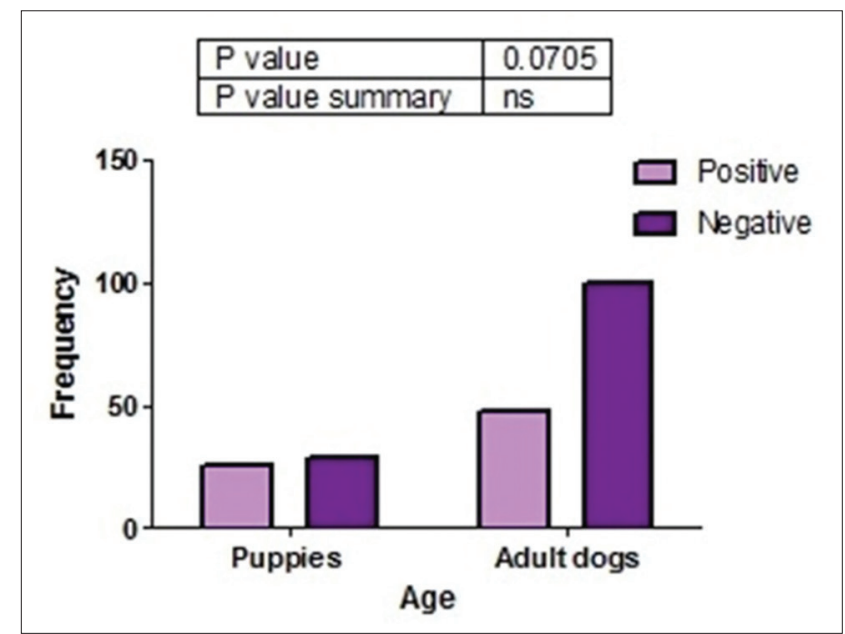

Figure-6: Association between the presence of Cryptosporidium spp. and age of dogs sampled in Enugu State, Nigeria. determined in this study. An overall high prevalence of $36.5 \%$ was recorded. High prevalence of cryptosporidiosis has also been recorded in other developing nations such as Costa Rica (75\%) [26] and South Africa (44\%) [22]. However, the high prevalence recorded in this study differed from the prevalence of 5.8\% obtained in dogs in Abuja, the capital of Nigeria [18]. This low prevalence in Abuja is similar to what was obtained in the developed countries such as the United States (3.8\%), Australia (9.4\%), and Japan (3.9\%) [27-29]. Furthermore, the prevalence of Cryptosporidium spp. obtained in China (3.8\%), Iran $(8 \%)$, and Zambia (5.9\%) is as low as those in developed countries $[7,19,30]$. The difference in the prevalence may be attributed to geographic location and standard of living, which determines the health care given to the pets. The level of education of pet owners, the reduced environmental contamination by dog's feces, as well as proper sewage disposal of human waste and efficient public refuse disposal systems help reduce the level of environmental contamination by the parasite oocysts and, hence, the low prevalence. In this study, we sampled dogs in rural areas where dogs are allowed to roam with little provision of veterinary health care and welfare, hence, the high prevalence.

In this study, we observed a strong association between the presence of Cryptosporidium spp. oocysts and management practice. It was observed that dogs managed semi-intensively had more Cryptosporidium spp. oocysts than those managed intensively. This is expected since those dogs' roam and thus are more predisposed to acquiring infections from the environment contaminated with human and dog feces. There was no statistically significant association between the presence of Cryptosporidium spp. oocysts and the age of dogs, although a higher prevalence of the parasite oocysts was seen in puppies than in adult dogs (Figure-6). This finding is in contrast with those of Olabanji et al. [18] and Mugala et al. [19] who reported that older dogs were more parasitized than puppies. Adults are said to have an increased tendency to roam and acquire the infection than puppies that have more restricted movement. However, our findings agree with those of Ramirez et al. [31], Hamnes et al. [32], and Jian et al. [7] who reported that puppies were more infected with Cryptosporidium spp. than adults. This may be due to immune incompetence in puppies, unlike older dogs.

Similarly, sex did not influence Cryptosporidium spp. infection as there were

Table-1: Distribution of Cryptosporidium spp. oocysts in six local government areas of Enugu State.

\begin{tabular}{lccc}
\hline Local government area & Fecal samples (n) & Positive (n) & Percentage \\
\hline Udenu & 61 & 22 & 36.1 \\
Igbo-Etiti & 34 & 15 & 44.1 \\
Ezeagu & 24 & 11 & 45.8 \\
Udi & 20 & 10 & 50.0 \\
Nsukka & 44 & 9 & 20.5 \\
Enugu North & 20 & 7 & 35.0 \\
Total & 203 & 74 & 36.5 \\
\hline
\end{tabular}


no significant associations $(p>0.05)$ between them, although there was a higher prevalence of Cryptosporidium spp. oocysts in male than female dogs which could be attributed to the fact that males move around more widely than females in search of mating partners and establishment of territory. This activity predisposes them to various kinds of infections, including intestinal protozoan infection. However, other workers reported higher infection in females than in males and attributed it to reduced immunity at certain periods in the female's physiologic cycle $[18,33,34]$.

Oocysts were seen more in apparently healthy dogs $(40 \%)$ than those having signs of enteritis (diarrhea) $-22 \%$ (watery feces) and 32\% (semi-solid feces). It appeared that the more the feces was formed, the higher the chances of presence of oocysts. Diarrhea is indicative of acute clinical cryptosporidiosis occasioned by the activities of the sporozoites and merozoites in the intestinal epithelia. Therefore, sufficient oocysts may not have been produced at the diarrheic phase to be shed in feces, especially as it has been observed that oocyst shedding in dogs infected with Cryptosporidium spp. occurs when the mature oocysts are formed following a successful asexual cycle [35]. This may have explained the reason for finding rather higher positive cases in formed feces. Our findings, in this work, are also in agreement with previous reports indicating that most infections in dogs are asymptomatic [7,19,31]. However, it contrasts with findings from other workers who reported seeing more oocysts in diarrheic feces $[18,20,21]$, particularly in young animals [36].

The locality had no significant association $(\mathrm{p}>0.05)$ with Cryptosporidium spp. infection. Nonetheless, Udenu had the highest (25\%) prevalence, followed by Igbo-Etiti $(20 \%)$. This may be because these areas are rural communities and have a higher density of dogs which are allowed to roam, the access to veterinary health care is low, and therefore these dogs are likely to have easy access to these oocysts from the environment. Therefore, dogs in such areas are predisposed to a high risk of contracting infections.

\section{Conclusion}

This study has established a high prevalence of Cryptosporidium spp. oocysts in domestic dogs in Enugu State, Nigeria. The rate of infection was higher in non-diarrheic and semi-intensively managed dogs. The presence of oocysts in feces by apparently healthy and free-roaming dogs poses public health risk to humans, immune-compromised adult animals, and puppies. Therefore, public health education and awareness of the zoonotic importance of these enteric protozoan parasites are imperative among dog owners and the general public. The infection should also be included in the list of routinely diagnosed diseases in veterinary hospitals and clinics as a possible cause of enteritis and diarrhea, as seen in this study.

\section{Authors' Contributions}

UUE and IOE conceived the work; TAN, SCA, and EVE collected and analyzed the samples; EV statistically analyzed the generated data; IOE, UUE, and DNO wrote, reviewed, and edited the manuscript. All authors read and approved the final manuscript.

\section{Acknowledgments}

The authors are thankful to Mrs. Nnaji, the senior laboratory technologist of the Department of Veterinary Parasitology and Entomology, Faculty of Veterinary Medicine, University of Nigeria, for technical support.

\section{Competing Interests}

The authors declare that they have no competing interests.

\section{Publisher's Note}

Veterinary World remains neutral with regard to jurisdictional claims in published map and institutional affiliation.

\section{References}

1. Slapeta, J. (2013) Cryptosporidiosis and Cryptosporidium species in animals and humans: A thirty color rainbow? Int. J. Parasitol., 43(12-13): 957-970.

2. O’Donoghue, P.J. (1995) Cryptosporidium and cryptosporidiosis in man and animals. Int. J. Parasitol., 25(2): 139-195.

3. Fayer, R. (2010) Taxonomy and species delimitation in Cryptosporidium. Exp. Parasitol., 124(1): 90-97.

4. Latif, B. and Rossole, N.F. (2015) Cryptosporidiosis among children with diarrhea in three Asian countries: A review. Asian Pac. J. Trop. Biomed., 5(11): 885-888.

5. Gatei, W., Barrett, D., Lindo, J.F., Eldemire-Shearer, D., Cama, V. and Xiao, L. (2008) Unique Cryptosporidium population in HIV-infected persons Jamaica. Emerg. Infect. Dis., 14(5): 841-843.

6. Elwin, K., Hadfield, S.J., Robinson, G. and Chalmers, R.M. (2012) The epidemiology of sporadic human infections with unusual cryptosporidia detected during routine typing in England and Wales, 2000-2008. Epidemiol. Infect., 140(4): 673-683.

7. Jian, F., Qi, M., He, X., Wang, R., Zhang, S., Dong, H. and Zhang, L. (2014) Occurrence and molecular characterization of Cryptosporidium in dogs in Henan province, China. BMC Vet. Res., 10: 26.

8. Xiao, L., Cama, V.A., Cabrera, L., Ortega, Y., Pearson, J. and Robert, H. (2007) Possible transmission of Cryptosporidium canis among children and a dog in a household. J. Clin. Microbiol., 45(6): 2014-2016.

9. Osman, M., El Safadi, D., Cian, A., Benamrouz, S., Nourrisson, C., Poirier, P., Pereira, B., Razakandrainibe, R., Pinon, A., Lambert, C., Wawrzyniak, I., Dabboussi, F., Delbac, F., Favennec, L., Hamze, M., Viscogliosi, E. and Certad, G. (2016) Prevalence and risk factors for intestinal protozoan infections with Cryptosporidium, Giardia, Blastocystis and Dientamoeba among schoolchildren in Tripoli, Lebanon. PLoS Negl. Trop. Dis., 10(3): e0004496.

10. Caccio, S.M. and Putignani, L. (2014) Epidemiology of human cryptosporidiosis. In: Caccio, S.M. and Widmer, G., editors. Cryptosporidium: Parasite and Disease. SpringerVerlag, Wien. p43-79.

11. Correa, R.F., Schild, A.L., Carmen, M.M., Tavares, A.S., Rodrigues, J.O. and Del Carmen Mendez, M. (1983) Claviceps paspali poisoning of cattle in Rio grande do Sul 
state, Brazil. Pesqui. Vet. Bras., 3(2): 59-65.

12. Dunbar, M.R. and Foreyt, W.J. (1985) Prevention of coccidiosis in domestic dogs and captive coyotes (Canis latrans) with sulfadimethoxine ormetropin combination. Am. J. Vet. Res., 46(9): 1899-1902.

13. Cynthia, M.K. (2005) The Merck Veterinary Manual. $9^{\text {th }}$ ed. Merck and Co. Inc., Whitehouse Station, New Jersey, USA. p168.

14. Dubey, J.P., Lindsay, D.S. and Lappin, M.R. (2009) Toxoplasmosis and other intestinal coccidial infections in cats and dogs. Vet. Clin. North Am. Small Anim. Pract., 39(6): 1009-1034.

15. Robertson, B., Sinclair, M.I., Forbes, A.B., Veitch, M., Kirk, M., Cunliffe, D., Willis, J. and Fairley, C.K. (2002) Case-control studies of sporadic cryptosporidiosis in Melbourne and Adelaide, Australia. Epidemiol. Infect., 128(3): 419-431.

16. Glaser, C.A., Safrin, S., Reingold, A. and Newman, T.B. (1998) Association between Cryptosporidium infection and animal exposure in HIV-infected individuals. J. Acquir. Immune Defic. Syndr. Hum. Retrovirol., 17(1): 79-82.

17. Cama, V., Gilman, H.R., Vivar, A., Ticona, E., Ortega, Y., Bern, C. and Xiao, L. (2006) Mixed Cryptosporidium infections and HIV. Emerg. Infect. Dis., 12(6): 1025-1028.

18. Olabanji, G.M., Maikai, B.V. and Otolorin, G.R. (2016) Prevalence and risk factors associated with fecal shedding of Cryptosporidium oocysts in dogs in the federal capital territory, Abuja, Nigeria. Vet. Med. Int., Vol.2016, Article ID 4591238.

19. Mugala, L., Siwila, J., Saasa, N. and Pandey, G.S. (2018) Prevalence of Cryptosporidium spp. Oocysts in dogs in Lusaka district of Zambia. Vet. World, 11(5): 585-589.

20. Tariuwa, H.O., Ajogi, I., Ejembi, C.L., Awah, I.J., Green, P.A., Fadipe, E.O. and Odoba, M.B. (2007) Incidence of Cryptosporidium infection in Port-Harcourt, Rivers state, Nigeria based on regular contact with domestic animals. Niger. Vet. J., 28(3): 3.

21. Makai, B.V., Umoh, J.U., Kwaga, J.K.P., Maikai, V. and Egege, S.C. (2009) Prevalence and risk factors associated with fecal shedding of Cryptosporidium oocysts in piglets, Kaduna state, Nigeria. J. Parasitol. Vector Biol., 1(1): 1-4.

22. Samie, A., Tsipa, M.A. and Bessong, P. (2013) The epidemiology of Cryptosporidium in cats and dogs in the Thohoyandou region, South Africa. Afr. J. Microbiol. Res., 7(21): 2510-2518.

23. National Agency for Control of Aids (NACA). (2016) Nigeria Prevalence Rate of HIV/AIDS. Plot 823, Ralph Shodeinde Street, Central Business District, Abuja.
Available from: https://naca.gov.ng/nigeria-prevalence-rate, Last accessed on 19-09-2018.

24. Ramirez, A., Olugasa, B. and Bickett-Weddle, D. (2004) Geographic Information System and its Role in Biological Risk Management. Center for Food Security and Public Health, 2160 Veterinary Medicine, Ames, Iowa USA. p50011.

25. Garcia, L.S. (2007) Diagnostic Medical Parasitology. $5^{\text {th }}$ ed. ASM Press, Washington DC. p813-816.

26. Scorza, A.V., Duncan, C., Miles, L. and Lappin, M.R. (2011) Prevalence of selected zoonotic and vector-borne agents in dogs and cats in Costa Rica. Vet. Parasitol., 183(1-2): 178-183

27. El-Ahraf, A., Tacal, J.V.J., Sobih, M., Amin, M., Lawrence, W. and Wilcke, B.W. (1991) Prevalence of cryptosporidiosis in dogs and human beings in San Bernardino County California. J. Am. Vet. Med. Assoc., 198(4): 631-634.

28. Palmer, C.S., Thompson, R.C.A., Traub, R.J., Ress, R. and Robertson, R.D. (2008) National study of the gastrointestinal parasites of dogs and cats in Australia. Vet. Parasitol., 151(2-4): 181-190.

29. Yoshiuchi, R., Matsubayashi, M., Kimata, I.I., Furuya, M., Tani, H. and Sasai, K. (2010) Survey and molecular characterization of Cryptosporidium spp. and Giardia spp. In owned companion animal, dogs and cats, in Japan. Vet. Parasitol., 174(3-4): 313-316.

30. Tavalla, M., Kord, E., Abdizadeh, R. and Asgarian, F. (2017) Molecular study of Cryptosporidium spp. In dogs from Southwest of Iran. Jundishapur J. Microbiol., 10(4): e43412.

31. Ramirez, N.E., Ward, L.A. and Sreevatsan, S.A. (2004) Review of the biology and epidemiology of cryptosporidiosis in humans and animals. Microbes Infect., 6(8): 773-785.

32. Hamnes, I.S., Gjerde, B.K. and Robertson, L.J. (2007) A longitudinal study on the occurrence of Cryptosporidium and Giardia in dogs during their first year of life. Acta Vet. Scand., 49: 22-32.

33. Wang, J., Li, P. and Xue, X. (2008) Investigation on the infection situation of Cryptosporidium in dogs in Hefei city. Chin. J. Vet. Parasitol., 16(5): 20-23.

34. Zelalem, G. and Mekonnen, A. (2012) Prevalence of gastrointestinal helminths among dogs in Bahir Dar town, Ethiopia. World Appl. Sci. J., 19(5): 595-601.

35. Juranek, D.D. (2000) Cryptosporidiosis. In: Strickland, G.T., editor. Hunter's Tropical Medicine and Emerging Infectious Diseases. $8^{\text {th }}$ ed. WB Saunders, Philadelphia, PA. p1192.

36. Ulutas, B. and Voyvoda, H. (2004) Cryptosporidiosis in diarrhoeic lamb on a sheep farm. Turk. Parazitol. Derg., 28(1): 15-17. 